\title{
Lodging markedly reduced the biomass of sweet sorghum via decreasing photosynthesis in saline-alkali field
}

\author{
Jian Rong Guo, Hai Fan, and Bao Shan Wang* \\ Key Lab of Plant Stress Research, College of Life Sciences, Shandong Normal University, Ji'nan, Shandong, 250014, P.R. China
}

\begin{abstract}
Lodging is a serious problem in plant growth, especially in crops growth of the natural habitat. In order to determine the influence of lodging on the growth characters of sweet sorghum, plants grown in natural saline-alkali environment were used to investigate the fresh weight, dry weight, sugar content in the stalks and the photosynthesis index of salt tolerant crop sweet sorghum. Results showed that lodging significantly reduced the growth of sweet sorghum, the fresh weight and dry weight was only $28.3 \%$ and $22.5 \%$ of the normal plants when lodging occurred after 49 days. Lodging also reduced the stalks sugar content of sweet sorghum, the stalk sugar content of lodged plants was only $45.4 \%$ of that in the normal plants, when lodging occurred for 49 days. Lodging reduced the growth and sugar content by reducing the photosynthesis parameters of sweet sorghum grown in the saline-alkali field, thus, affected the accumulation of photosynthate. Interestingly, with the extension of the lodging time, lodging led to a decrease in photosynthetic rate of sweet sorghum mainly due to non-stomatal factors.
\end{abstract}

\section{Introduction}

Soil salinization is an increasing problem throughout the world. Nearly $10 \%$ of the soils were affected by salt in the world and there are $50 \%$ in irrigated land $[1,2]$. Furthermore, the seedling growth and the yield of salt sensitive crops were significantly inhibited when grown in such environments [3], while the salt-tolerant plants could grow well in such conditions [4], and salt-tolerant crops cultivated in saline-alkali soils could be considered as the most economical and effective way to use and improve saline-alkali land. Therefore, revealing the cultivation techniques of salt-tolerant crops on salinealkali soil is necessary for the better utilization of salinealkali soil.

High crop yields must have a good and complete growth cycle from seedling to harvest. Lodging is one of the important factors which limit crop growth and yield in the growth period [5]. There are two types of lodging, stem lodging and root lodging [6]. Lodging will be affected by plant's own and environmental factors, high plant density and high level of nitrogen fertilization could directly influence the growth of crops, thereby reducing the lodging resistance of crops [7, 8], the lodging resistance is also related to the developmental stages of crops [7]. The environmental factors, such as rain, wind and together could cause crop lodging [9], therefore, crop lodging mainly occurred in the rainy season with wind. When lodging occurs, the absorptive capacity of plants would be destroyed, water and minerals transportation was blocked, as while as the capacity of photosynthetic rate and the dry mass were reduced, thus leading to a decline in the yield and quality of plants [10]. For example, lodging reduced the biomass production and cane quality in sugarcane, so lowered the productivity of sugarcane [11]. In rice, lodging at one day before the grain-filling stage reduced the yield, decreased the seed-setting percentage, reduced the 1000grain weight, subsequently lower the eating quality [12]. Lodging at different development stage may have different impact on the growth of plants. Artificial lodging experiments for oilseed rape indicated that, lodging during flowering, the yield of oilseed rape could reduce by $50 \%$, approximately, while the yield lost was smaller when the lodging occurred during seed filling, but the maximum decrease in seed oil content when lodging occurred at early flowering [13]. However, it remains unknown that whether or not the growth and the yield of sweet sorghum also decreased by lodging when grown in the saline-alkali field.

Sweet sorghum [Sorghum bicolor (L.) Moench] is a $\mathrm{C}_{4}$ crop that can grow in saline-alkali environment, and it is an important raw material employed as ethanol production and fodder [14]. Additionally, sweet sorghum has high salt tolerance in seed germination and seedling growth, and it can complete the life cycle under salinealkali environment. And the tolerance of sweet sorghum to saline environment seems to be related to the ability to avoid the excessive accumulation of harmful ions of $\mathrm{Na}^{+}$ and $\mathrm{Cl}^{-}$, and keeping a certain concentration of $\mathrm{K}^{+}$, especially in shoot [15]. Compared with ordinary sorghum crops, sweet sorghum can be used in a wide range of applications, because of the characteristics of high biomass and high sugar content in its stalks [16]. There are a lot of saline-alkali lands in the Yellow River Delta of Shandong, and it has high economic values for

\footnotetext{
* Corresponding author: bswang@sdnu.edu.cn
} 
using and developing saline-alkali soils by planting sweet sorghum in such environment. Therefore, it is necessity to investigate the cultivation technology of sweet sorghum in saline-alkali soils. The lodging of sweet sorghum was found during the cultivation after the heavy rain in the summer, so the changes and the reasons in physiological indicators of sweet sorghum after lodging were analyzed.

Based on the above analysis, the objective of this study was therefore to determine the effect of nature lodging in sweet sorghum on the growth, sugar content and photosynthesis when grown in saline-alkali soil, thus may help to find the suitable cultivation techniques for planting sweet sorghum on saline-alkali fields.

\section{MATERIALS AND METHODS}

\subsection{Plant materials and growth conditions}

Sweet sorghum (Sorghum bicolor L. Moench) seeds were sown in the field at Dongying (N 37 $27^{\prime}$; E $\left.118^{\circ} 30^{\prime}\right)$, province of Shandong (north China). The field experiments were conducted during 2016/06-2016/11 in the growing seasons. The salinity of the soil was 0.34 $0.63 \%$. Rainfall from sowing to maturity was $430-460$ $\mathrm{mm}$ mainly concentrated in July and August, the lodging of sweet sorghum occurred at August 26 after intense rainfall and wind at 91 days after sown, and the lodging rate was $52.1 \%$ approximately.

\subsection{Growth assessment}

To check if lodging affects the growth and dry mass material accumulation of sweet sorghum, at different growth time after lodging, the above-ground parts of six replicate sweet sorghum plants from normal and lodging, respectively, were harvested and put to the laboratory. The plants were washed with distilled water. After the distilled water on the plant was dried by filter paper, the fresh weight (FW) was measured. The dry weight (DW) was measured after the fresh material was dried in an oven at $105^{\circ} \mathrm{C}$ for $10 \mathrm{~min}$ then turned to $80^{\circ} \mathrm{C}$ for $72 \mathrm{~h}$.

\subsection{Stalk sugar content determination}

In order to determine whether the sugar content in the stalk of sweet sorghum was influenced by lodging, at different growth time after lodging, six replicates of sweet sorghum plants from normal and lodging, respectively, were selected. The same section, No. 7 counted from the bottom, was harvested, and the juice was extracted by squeezing. Then, the total sugar content in the juice was determined by using a hand sugar meter (WYT-5, China) according to [14].

\subsection{Photosynthesis determination}

In order to determine whether the photosynthesis of sweet sorghum was influenced by lodging, at different growth time after lodging, thirty replicates of sweet sorghum plants from normal and lodging, respectively, were selected. Net photosynthetic rate, stomatal conductance, intercellular $\mathrm{CO}_{2}$ concentration and transpiration rate of the functional leaves were measured with a portable photosynthesis system (CIRAS-3, PPS, USA).

\subsection{Statistical analysis}

The statistical results are described as means \pm s.d., where $\mathrm{n}$ is the number of replicates. The data were analysed using the statistical software SPSS ver. 17.0 (SPSS Inc.) and one-way ANOVA software packages. Different letters in the table and figures indicate significant difference among the means (at 0.05) according to Duncan's test.

\section{Results}

\subsection{Lodging reduced the fresh weight and dry weight of sweet sorghum}

In order to analyze the effect of lodging on the growth and the stalk yield of sweet sorghum grown in the salinealkali field, the whole plant above ground was harvested, the fresh and dry weight of the individual sweet sorghum plant was determined at different times (September 2, September 23 and October 14) after lodging at August 26 due to heavy rainfall and wind. The results showed that, after lodging occurred, the growth of sweet sorghum was inhibited when compared with the normal plants, and the inhibitory effect becomes more pronounced as the lodging time increases. Compared with the normal plants, when lodging for 7 days, the fresh weight and dry weight of sweet sorghum decreased significantly, which were $82.2 \%$ and $55.2 \%$ of the normal plants, respectively. When the lodging time was 28 days, the fresh weight and dry weight were $40.9 \%$ and $38.2 \%$ of the normal plants, respectively. But when the lodging time increased to 49 days, the fresh weight and dry weight of sweet sorghum plants decreased extremely significantly, which only were $28.3 \%$ and $22.5 \%$ of the normal plants (Fig. 1). This result indicated that lodging markedly affected the biomass of sweet sorghum plants. 


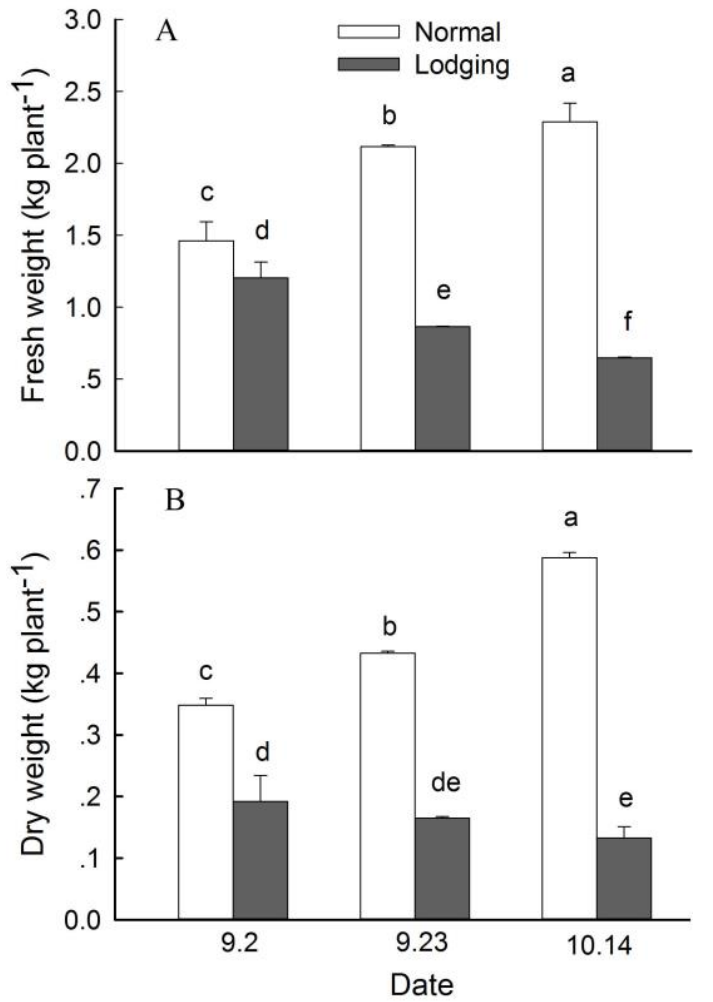

Fig. 1. Fresh weight (A) and dry weight (B) of sweet sorghum of the normal and lodging plants in the field, at different harvest date in the year of 2016. The data are described as the means \pm s.d. of six replicate plants. Different letters indicate significant differences at the level of 0.05 .

\subsection{Lodging reduced the sugar content of sweet sorghum}

Lodging reduced the accumulation of sweet sorghum material, whether did lodging also affect the sugar content of sweet sorghum stalks, so the stalk sugar content was determined at different times (September 2, September 23 and October 14) after lodging at August 26. The results showed that, lodging significantly reduced the content of sugar in the stalk of sweet sorghum, and the sugar content in the stalk decreased more significantly with the extension of lodging time. Compared with the normal plants, when lodging for 7 days, the sugar content in the stalk of lodging plants was $81.1 \%$ of the normal plants. When the lodging time increased to 49 days, the sugar content in the stalk of lodging plants was only $45.4 \%$ of the normal plants (Fig. 2 ). The results indicated that the lodging may affect the accumulation of photosynthate, thus reduce the sugar content of sweet sorghum.

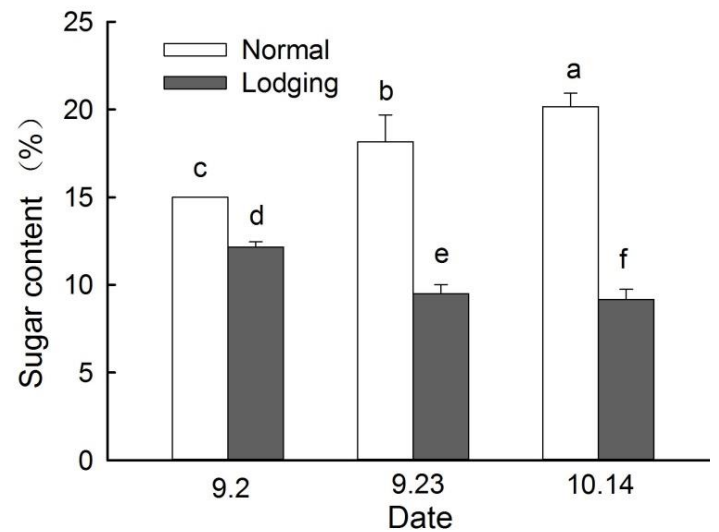

Fig. 2. Sugar content in the stalk of the No. 7 section, counted from bottom of sweet sorghum from the normal and lodging plants in the field, at different harvest date in the year of 2016.

The data are described as the means \pm s.d. of six replicate plants. Different letters indicate significant differences at the level of 0.05 .

\subsection{Lodging reduced the net photosynthetic rate and stomatal conductance of sweet sorghum}

In order to analyze the effect of lodging on the photosynthesis parameters of sweet sorghum grown in the saline-alkali field, the net photosynthetic rate and the stomatal conductance of the functional leaves of sweet sorghum plant was determined at different time (September 2 and September 23) after lodging at August 26 . The results showed that lodging significantly reduced the net photosynthetic rate of sweet sorghum leaves (Fig. $3 \mathrm{~A})$. Compared with the normal plants, when lodging for 7 days, the net photosynthetic rate of sweet sorghum leaves was $60.6 \%$ of the normal plants. When the lodging time increased to 28 days, the net photosynthetic rate of the leaves of the lodging plants was only $13.4 \%$ of normal plants. The results from the stomatal conductance of sweet sorghum leaves were consistent with the net photosynthetic rate results. When lodging for 7 days, the stomatal conductance of sweet sorghum leaves was $66.9 \%$ of the normal plants, while the stomatal conductance was $41.0 \%$ of the normal plants, when the lodging time increased to 28 days (Fig. 3B). The result of transpiration rate was consistent with stomatal conductance (Fig. 3C). Interestingly, with the extension of the lodging time, the decline degree of intercellular $\mathrm{CO}_{2}$ concentration was significantly less than the degree of photosynthesis, it was only $70.7 \%$ of the normal plants at the day 28 after lodging, when the lodging time increased to 28 days (Fig. 3D). Lodging led to a decrease in photosynthetic rate of sweet sorghum due to stomatal factors in the early stage, and nonstomatal factors in the later stage after lodging. 


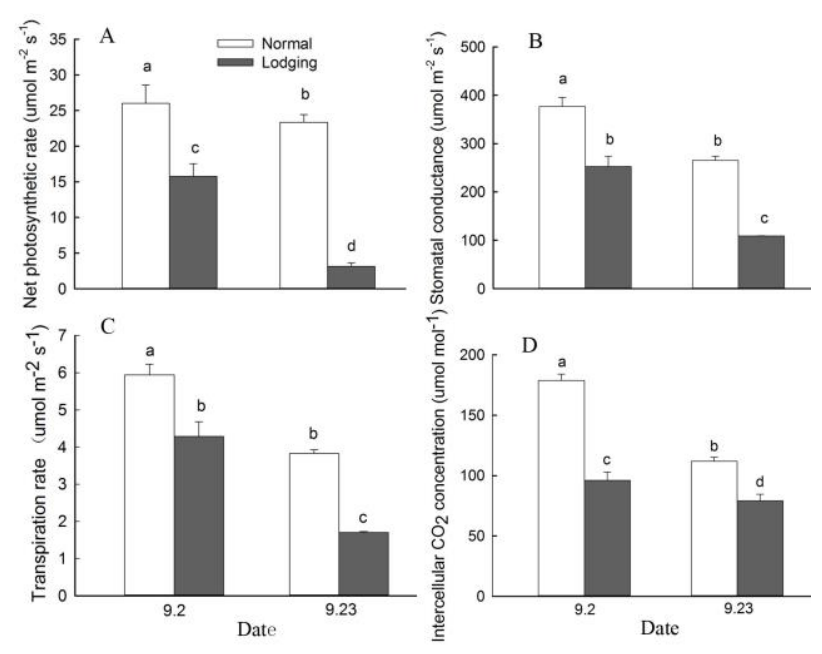

Fig. 3. Net photosynthetic rate (A), stomatal conductance (B), transpiration rate (C) and intercellular $\mathrm{CO}_{2}$ concentration (D) of sweet sorghum from the normal and lodging plants in the field, at different harvest date in the year of 2016. The data are described as the means \pm s.d. of thirty replicate plants.

Different letters indicate significant differences at the level of 0.05 .

\section{Discussion}

Lodging had a consistently negative effect on crop growth [17], sugar accumulation [11] and seed yield [18]. In the present paper, for the first time, the effect of lodging on the plant growth, sugar accumulation and photosynthetic parameter of sweet sorghum when cultivated in the saline-alkali soil was investigated. Sweet sorghum has high salt tolerance and can be grown in saline-alkali habitat, and can be used as fodder and fuel ethanol [14]. Therefore, it has a crucial significance for the utilization of saline-alkali land by cultivating sweet sorghum in saline-alkali soil. While, high percentage of lodging often occurred because of heavy rainfall in the experimental field of Dongying during the growth period of sweet sorghum. Thus, it is very important to understand the lodging effect on sweet sorghum when planting on saline-alkali soils.

Biomass yield of crops will be reduced by lodging $[17,19]$. In the present study, the fresh weight and dry weight of individual sweet sorghum plant was significantly decreased after lodging (Fig. 1A), and which was gradually decreased with the increase of lodging time when compared with the normal plants, thus reduces the harvest index and total yield of sweet sorghum, and which is unfavorable for fodder and fuel ethanol production. Just like the growth in wheatgrass, lodging resulted in a severe of crop loss [20].

Stalk sugar content is an important indicator of sweet sorghum use as bioenergy feedstock, with the growth progresses, large amounts of sugars accumulated in sweet sorghum stalks, especially in saline-alkali habitats [21]. But the sugar content in sweet sorghum stalks significantly reduced when lodging occurred for 7 days (Fig. 2), and with the increase of lodging time, the sugar content in stalks decreased more significantly. The sugar and dry matter accumulation of plant comes from the photosynthesis of plants, lodging reduced the sugar and dry weight of individual sweet sorghum plant, so, what about the photosynthetic index of sweet sorghum plants after lodging. From the detection of the net photosynthesis of the lodging plants, we found that the net photosynthesis of the lodged plants was significantly reduced (Fig. 3), as while as the stomatal conductance. As showed in rice, lodging reduced the yield of rice by the reductions in photosynthesis [22]. At 7 days after lodging, the net photosynthetic rate of sweet sorghum leaves decreased in a similar as that of the stomatal conductance, while, with the extension of the lodging time, the decrease of net photosynthetic rate was more significantly than that of the stomatal conductance and the intercellular $\mathrm{CO}_{2}$ concentration. Therefore, at early lodging, the decline of the net photosynthetic rate may be due to stomatal factors, with the lodging time is prolonged, the decline of the net photosynthetic rate of lodged sweet sorghum plants may mainly be because of non-stomatal limitation factors. Long period of lodging maybe resulted in the damage of the photosynthetic system, reduced the using efficiency of carbon dioxide, thus reduced the net photosynthetic rate.

\section{Conclusions}

Sweet sorghum can be used as feedstock for fuel ethanol and livestock husbandry. Sweet sorghum has strong salt resistance and can grow in the saline-alkali environment, so it is a good material for the utilization and development of saline-alkali soil. Lodging markedly reduced the fresh weight, dry weight and the sugar content in the stalks of sweet sorghum, and the decrease of matter accumulation mainly due to the decline of photosynthesis. So, it is important to improve the lodging resistance of sweet sorghum in the field, future studies should focus on the fertilizer supply and hormone regulation in nature growth conditions.

\section{Acknowledgements}

This work was supported by the National Natural Science Foundation of China (31570251 and 31770288), the independent innovation and achievement transformation of special major key technical plans of Shandong Province (2015ZDJS03002 and 2017CXGC0313), the Natural Science Research Foundation of Shandong Province (ZR2017MC003), and the Higher Educational Science and Technology Program of Shandong Province (J17KA136).

\section{References}

1. J. Song, W. Shi, R. Liu, Y. Xu, N. Sui, J. Zhou, Plant Spec. Bio. 32, 2 (2016)

2. J. Guo, S. Suo, B. Wang, Seed Sci. Res. 25, 3 (2015)

3. L. Kotula, H.A. Khan, J. Quealy, N.C. Turner, V. Vadez, K.H. Siddique, P.L. Clode, T.D. Colmer, Plant Cell Environ. 38, (2015)

4. J. Guo, Y. Li, G. Han, J. Song, B. Wang, Funct. Plant Biol. 45, 3( 2018) 
5. A.S. Peake, K.L. Bell, P.S. Carberry, N.Poole, S.R. Raine, Crop and Pasture Sci. 67, 9 (2017)

6. M.M. Sposaro, P.M. Berry, M. Sterling, A.J. Hall, C.A. Chimenti, Field Crops Res. 119, 1 (2010)

7. M.M. Sposaro, C.A. Chimenti, A.J. Hall, Field Crops Res. 106, 2 (2008)

8. M. Podgórska-Lesiak, P. Sobkowicz, Field Crops Res. 149, (2013)

9. P. Martinez-Vazquez. Agri. Forest Meteorol. 228229, (2016)

10. T. Kashiwagi, H. Sasaki, K. Ishimaru, Plant Prod. Sci. 8, 2 ( 2005)

11. P.D.R. van Heerden, A. Singels, A. Paraskevopoulos, R. Rossler, Field Crops Res. 180, (2015)

12. Y.Z. Lang, X.D. Yang, M.E. Wang, Q.S. Zhu, Rice Sci. 19, 4 (2012)

13. S.L. Kendall, H. Holmes, C.A. White, S.M. Clarke, P.M. Berry, Field Crops Res. 211, (2017)

14. S. Audilakshmi, A.K. Mall, M. Swarnalatha, N. Seetharama, Biomass \& Bioenergy 34, 6 (2010)

15. A. Almodares, M.R. Hadi, B. Kholdebarin, B. Samedani, Z.A. Kharazian, J. Environ. Biol. 35, 4 (2014)

16. A. Goshadrou, K. Karimi, M.J. Taherzadeh, Ind. Crop Prod. 34, 1 (2011)

17. G. Singh, S.G. Chapman, P.A. Jackson, R.J. Lawn, Aust. J. Agr. Res. 53, 11 (2002)

18. Y. Xiao, J. Liu, H. Li, X. Cao, X. Xia, Z. He, Frontiers Agr. Sci. Engin. 2, 2 (2015)

19. J.A. Rueda, E. Ortega-Jiménez, A. HernándezGaray, J.F. Enríquez-Quiroz, J.D. GuerreroRodríguez, A.R. Quero-Carrillo, Biomass and Bioenerg. 88, (2016)

20. M.M. Acreche, G.A. Slafer. Field Crops Res. 122, (2011)

21. N. Sui, Z. Yang, M. Liu, B. Wang, BMC genomics 16, 1 (2015)

22. T.L. Setter, E.V. Laureles, A.M. Mazaredo, Field Crops Res. 49, (2-3) (1997) 